\title{
Extensive Delayed Brain Atrophy after Resuscitation in a Patient with Multiple System Atrophy
}

\author{
Sazuku Nisitani*, Hirofumi Miyoshi and Yoji Katsuoka \\ Port Island Hospital, Kobe, Japan
}

Brain magnetic resonance imaging (MRI) of multiple system atrophy (MSA) shows atrophy in the cerebrum, cerebellum, and brainstem. It is also characterized by specific patterns such as hyperintense lateral putaminal rim. MRI of hypoxic encephalopathy shows atrophy mainly in the gray matter, and laminar necrosis in the cerebral cortex is often observed. Here, we report an MSA patient damaged by hypoxic insult and resuscitated after 18-min cardiac arrest. The brain of the patient developed severe atrophy within a period of 10 months. Furthermore, brain atrophy was observed in the white and gray matter, which preserved the brain atrophy pattern in MSA. We assume that alpha-synuclein oligomerization is involved in the neural cell death and brain atrophy. It might have caused further neural cell death in the brain damaged by hypoxia. Alphasynuclein, which is involved in the pathogenesis of MSA, is suggested to be a prion.

Alain Kaelin-Lang,

Neurocenter of Southern Switzerland

(NSI), Switzerland

Reviewed by: Pedro Ribeiro,

Universidade Federal do Rio de Janeiro, Brazil

Manuel Bertschi,

Kantonsspital Aarau, Switzerland

${ }^{*}$ Correspondence:

Sazuku Nisitani

port_island_hospital@yahoo.co.jp

Specialty section:

This article was submitted to

Movement Disorders,

a section of the journal

Frontiers in Neurology

Received: 07 July 2017

Accepted: 28 December 2017

Published: 15 January 2018

Citation:

Nisitani S, Miyoshi H and Katsuoka Y (2018) Extensive Delayed Brain

Atrophy after Resuscitation in a Patient with Multiple System Atrophy.

Front. Neurol. 8:754.

doi: 10.3389/fneur.2017.00754
Misfolded alpha-synuclein may propagate through cell-to-cell transmission and cause wide pathological change, visible as atrophied MR imaging.

Keywords: multiple system atrophy, hypoxic encephalopathy, brain atrophy, magnetic resonance imaging, resuscitation, alpha-synuclein

\section{BACKGROUND}

Multiple system atrophy (MSA) is a progressive neurodegenerative disease. MSA patients show phenotypes characterized by autonomic failure with motor involvement of parkinsonism and/or cerebellar ataxia. Autonomic dysfunction of MSA includes orthostatic hypotention, bowel and bladder disturbances, and erectile dysfunction in males $(1,2)$. MSA patients survive between 6.2 and 10 years, but some MSA patients survive for over 15 years (3). MSA comprises MSA-C (with cerebellar symptoms) and MSA-P (developing Parkinsonism). In MSA-C, the olivary nucleus, pons, and cerebellum cortex become atrophic. In MSA-P, the dorsolateral regions of both putamina are atrophic $(4,5)$. Several features of magnetic resonance imaging (MRI) have been identified in MSA. In MSA-P, there appears a bilateral T2-hyperintense rim, bordering the dorsolateral margins of the putamen ("hyperintense lateral putaminal rim") and T2-putaminal hypointensity (6). In MSA-C, there appears a T2-hyperintense cross in the pons ("hot-cross-bun sign") [reviewed in Ref. (7)]. MSA patients have narrower middle cerebellar peduncle and wider superior cerebellar peduncle compared to those of progressive supranuclear palsy (PSP) patients (8).

Abbreviations: CJD, Creutzfeldt-Jakob disease; CT, computed tomography; DWI, diffusion-weighted image; ER, endoplasmic reticulum; FLAIR, fluid-attenuated inversion recovery; GCI, glial cytoplasmic inclusion; H/M, heart-to-mediastinum; MIBG, metaiodobenzylguanidine; MRI, magnetic resonance imaging; MSA, multiple system atrophy; NCI, neuronal cytoplasmic inclusion; PSP, progressive supranuclear palsy; VSRAD, voxel-based specific regional analysis system for Alzheimer's disease. 
In MSA, mechanisms of neural cell death, which underlies brain atrophy, are unresolved. However, the involvement of alphasynuclein in the neural cell death has been suggested by sizable number of evidences. Alpha-synuclein oligomers accumulate in the brain of the MSA patients to induce metabolic imbalance, which might promote neural cell death (9). Other mechanisms of the neural cell death in MSA include proteasomal or autophagosomal dysfunction and excitotoxicity [reviewed in Ref. (10)].

Brain MRIs of the patients developing hypoxic encephalopathy after cardiac arrest show different features. The diseased state and brain imaging findings vary and are influenced by age, baseline disease, and cardiac arrest period (11). In resuscitated and completely recovered patients, specific computed tomography (CT) imaging features are barely detectable. In the acute phase, the gray matter gives high-density signals on MRI (12). These signals increase in T2 and fluid-attenuated inversion recovery images by performing MRI after the subacute phase. By contrast, the signal intensity in the white matter rarely increases in such patients. Laminar necrosis in the cerebral cortex is often observed in hypoxic encephalopathy patients. Among hypoxic encephalopathy patients, those with hypoxic encephalopathy caused by cardiac arrest develop extensive global brain atrophy (12-16). It is well known that the gray matter is extensively damaged by hypoxic insult (12). However, whether the white matter is as severely damaged as the gray matter by hypoxic insult remains unknown.

\section{CASE PRESENTATION}

A 65-year-old man developed Parkinsonism with resting tremor in his right hand, bradykinesia, and cerebellar dysarthria 10 years previously, from his death at 75 years of age in January 2017. He sometimes developed orthostatic hypotension. He also developed urinary incontinence with constipation. Postural reflex failure, finger-dexterity deficits, gait disturbance, and freezing of gait followed. He also developed irritability and memory deficit, but not cognitive impairment. When he previously visited a doctor in November 2008, no vertical gaze palsy had been noted and Babinski reflexes of both sides were observed. The early and delayed heart-to-mediastinum (H/M) uptake ratios on performing ${ }^{123}$ I-metaiodobenzylguanidine (MIBG) scintigraphy were 1.8 and 1.7, respectively (Ogura J: personal communication). His brothers, sisters, or children had no neurodegenerative disorders. He developed rigidity of the trunk and upper and lower limbs. Levodopa treatment (600 mg per a day) did not improve his Parkinsonism.

In August 2015, caregivers at the home for elderly people, where the patient resided, found him in cardiac arrest and transferred him to the hospital. When a doctor tried to intubate him, he found that the airway was obstructed by a piece of bread and removed it with Magill forceps. However, it took $18 \mathrm{~min}$ to find and remove the obstruction. The patient was intubated, received therapeutic hypothermia at $33^{\circ} \mathrm{C}$, was rewarmed after $24 \mathrm{~h}$, had recovered to $37^{\circ} \mathrm{C}$ by $48 \mathrm{~h}$ after starting hypothermia, and was then extubated. The corticomedullary junction was unclear in the CT scan, which suggested hypoxic encephalopathy. The patient was in mutative akinesia, and it was estimated that levodopa would not improve the disease; the amount of levodopa was reduced to $300 \mathrm{mg}$. Because of aggravation of dysphagia and bladder rectal disorders such as dysuria, he was admitted to our hospital in September 2015 in a bedridden state. At that time, he was fed liquid nutrition using nasal tube and could speak, but with cerebellar dysarthria. We observed the Babinski reflex and Chaddock reflex on both sides and the snout reflex. Orthostatic hypotension was also observed. He developed rigidity in the neck and upper and lower limbs. We increased the amount of levodopa up to $600 \mathrm{mg}$ per day, but could not improve his Parkinsonism.

Computed tomography assessment showed no apparent atrophy in the cortical region or brainstem in September 2015 (Figure 1). There was slight atrophy in the medial temporal lobe and slight dilatation of the lateral ventricles and Sylvian fissures. By contrast, marked atrophy of the cerebrum, brainstem, and cerebellum was observed by CT and MRI in July 2016 and after August 2016, respectively (Figures 1-3). Atrophy was observed in the midbrain, caudal pons, and striata on both sides ("hyperintense lateral putaminal rim") (Figures 2 and 3), which strongly indicated MSA. The lateral, third, and fourth ventricles were markedly dilated. Measurement of the T1-weighted mid-sagittal
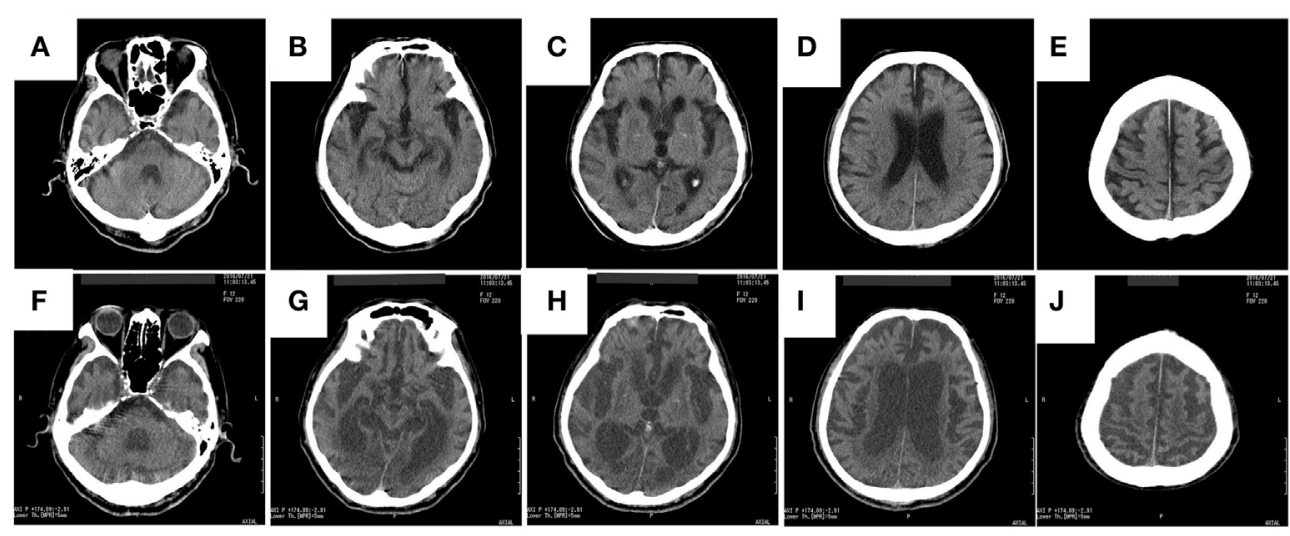

FIGURE 1 | The rapid progress of brain atrophy in the MSA patient after developing hypoxic encephalopathy axial CT images of the patient acquired in September 2015 (A-E) and in July 2016 (F-J) are shown. MSA, multiple system atrophy; CT, computed tomography. 


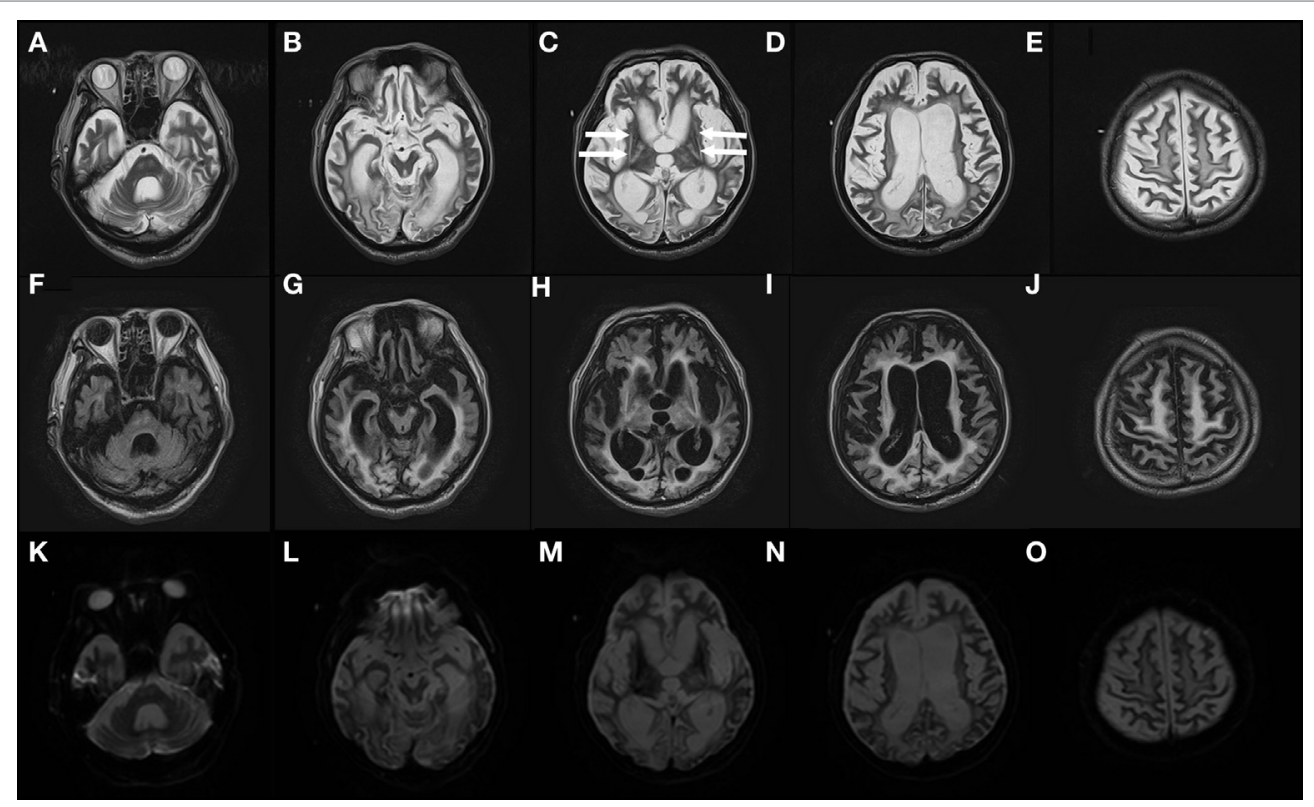

FIGURE 2 | Severe atrophy in the MSA patient's brain observed in August 2016 Gadolinium-enhanced MRI T2 images (TR: 4,800 ms, TE: 105 ms) (A-E), fluid-attenuated inversion recovery images (TR 10,000 ms, TE 120 ms) (F-J), and diffusion-weighted imaging images (TR 5,400 ms, TE 100 ms) (K-O) of the patient's brain in August 2016 are shown. Arrows in (C) indicate dorsolateral regions of atrophy ("hyperintense lateral putaminal rim"). MSA, multiple system atrophy; MRI, magnetic resonance imaging.

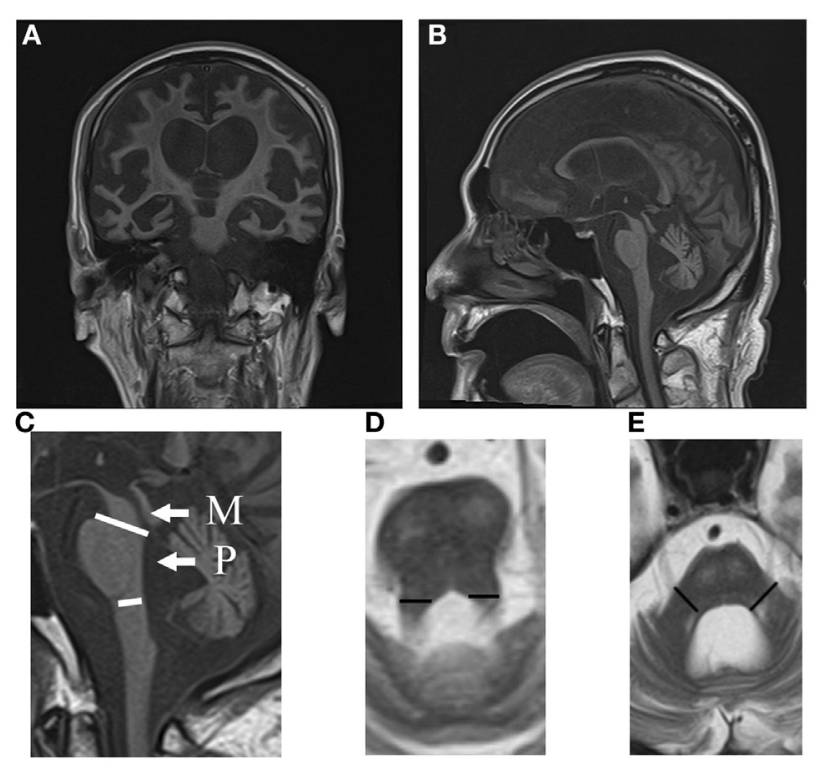

FIGURE 3 | MRI coronal (A) and sagittal (B) T1 images (TR $540 \mathrm{~ms}$, TE $15 \mathrm{~ms}$ ) of the MSA patient in August 2016. Note the atrophy in the caudal pons. The midbrain and cerebellum are atrophic. (C) Areas of the midbrain (M) and pons (P) are shown. (D) The width of the superior cerebellar peduncles (segments) is shown. (E) The width of the middle cerebellar peduncles (segments) is shown. MSA, multiple system atrophy; MRI, magnetic resonance imaging.

image and T2-weighted axial images showed that the midbrain area and pons area were 75.3 and $321.2 \mathrm{~mm}^{2}$, respectively, and the mean widths of the superior cerebellar peduncles and middle cerebellar peduncles were 3.38 and $11.25 \mathrm{~mm}$, respectively, as measured in the same manner as described in a previous study (8) (Figures 3C-E). Compared with the results in the previous report (8) (median area of the pons: $331 \mathrm{~mm}^{2}$; median width of the middle cerebellar peduncle, $11.7 \mathrm{~mm}$; median width of the superior cerebellar peduncle, $3.3 \mathrm{~mm}$ ), our results were consistent with the pattern of images associated with MSA, except for the highly atrophic midbrain, which might indicate the possibility of PSP. It should be noted that atrophy of the middle cerebellar peduncles, rather than the superior cerebellar peduncles, is a feature of MSA images.

Use of the voxel-based specific regional analysis system for Alzheimer's disease (17-19) software according to the method used in previous studies on the same regions $(18,19)$ showed that the white and gray matter atrophy values were 77.36 and $80.49 \%$, respectively, with a $z$-score $>2$ in October 2016 (Figure 4). From the time of admission, aspiration pneumonia occurred repeatedly and finally led to death in January 2017. At the request of the bereaved family, an autopsy was not performed.

\section{DISCUSSION}

The patient presented in this report had developed a sporadic, progressive, adult-onset disease characterized by poorly levodoparesponsive parkinsonism. He also developed autonomic failure, involving urinary incontinence and orthostatic hypotension, as well as cerebellar dysarthria. These symptomatic features fulfill the diagnostic criteria of "probable MSA" (4). He might belong to an atypical MSA, in that he lived 10 years after the onset of the disease. This might be partly due to our extensive care, nursing, and rehabilitation. Furthermore, a previous report described 


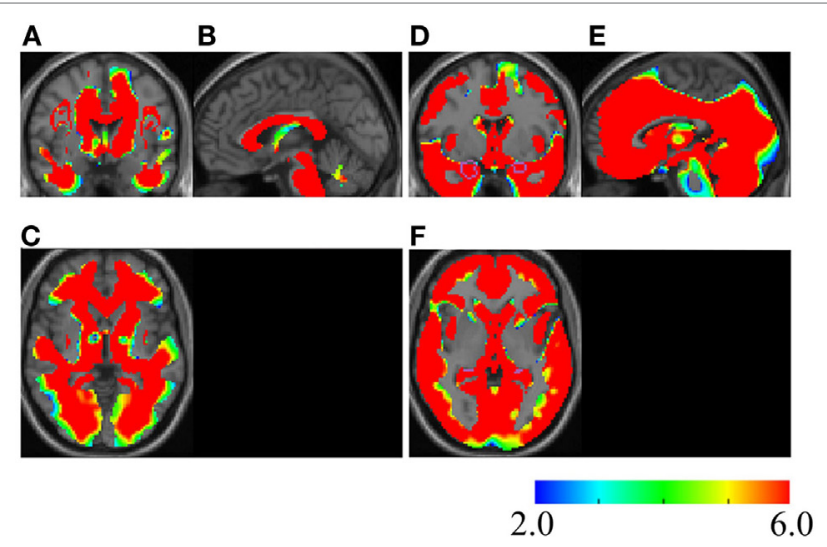

FIGURE 4 | Severe atrophy in the white and gray matter of the MSA patient. Z-score maps of the white matter (A-C) and gray matter (D-F) of the MSA patient are shown. The brain image of the patient is compared with that of individuals without neurodegenerative diseases or dementia (17). The color scale for the $z$-score is shown on the bottom right. Colored areas indicating a $z$-score of $>2$ are overlaid as regions of significant atrophy. Coronal $(\mathbf{A}, \mathbf{D})$, sagittal $\mathbf{( B , E )}$, and axial (C,F) sections by magnetic resonance imaging (MRI) are presented on a standardized MRI template. Regions with a $z$-score of $>6$ exist widely in the patient's brain, regardless of whether the region belongs to the white or gray matter. [Regions inside the purple polygons are medial temporal lobes, because the initial aim of the voxel-based specific regional analysis system for Alzheimer's disease software creators was estimation of the atrophy rate of the area (17)]. MSA, multiple system atrophy.

some MSA patients survived over 15 years (3). This diagnosis is supported by images showing, for example, atrophy in the dorsolateral regions of the putamina (Figures $\mathbf{2 C}, \mathbf{H}$ ), and atrophy in the cerebellum and caudal regions of the pons (Figure 3B).

Our patient exhibited moderate decrease in uptake of MIBG, whereas a marked decrease in MIBG uptake in patients with Parkinson disease and those who have dementia with Lewy bodies has been reported in many studies. The moderate reduction in uptake by our patient supports a diagnosis of MSA, as suggested by some previous studies (20-22). Literature on the H/M ratios of MSA, PSP, Parkinson disease, and healthy controls in MIBG scintigraphy has been reviewed by Chung and Kim (23). We searched the literatures in their review, and calculated mean \pm SD using the representative value and $\mathrm{N}$ from each literature, and compared them with our $\mathrm{H} / \mathrm{M}$ ratios (early, 1.8; late, 1.7) and examined the estimated $p$-values, provided that the data were from normally distributed data. $\mathrm{H} / \mathrm{M}$ ratios of the patient are more likely to be those in MSA (early: $p=0.175>0.1$; delayed: $p=0.137>0.1$ ) rather than those in Parkinson disease (early: $p<0.1$; delayed: $p<0.01$ ) nor PSP (early: $p<0.05$; delayed: $p<0.05$ ). The data of the patient declined from those of the normal control (early: $p<0.1$; delayed: $p<0.01$ ).

Next, we performed a differential diagnosis by considering other diseases with symptoms resembling MSA-P. Parkinson disease was excluded because Parkinsonism of the patient responded poorly to $600 \mathrm{mg}$ levodopa per day. Creutzfeldt-Jakob disease (CJD) was also excluded because diffusion-weighted imaging gave no sign of high intensity, which was typical for images of CJD. Corticobasal degeneration was excluded because the patient did not show cortex symptoms that matched the diagnostic criteria
(24). The symptoms of the patient did not fit the one major criteria of probable PSP: vertical gaze palsy (25) although previous reports have suggested that $10-50 \%$ of the patients diagnosed with PSP did not develop vertical gaze palsy (25).

A limitation of this study was that we could not obtain permission for an autopsy, so we could only provide a probable diagnosis.

Progression of symptoms, pathological aspects, and MSA brain imaging findings of longitudinal studies have been reported. Whole-brain atrophy rates in MSA have been $1.65 \pm 1.12$ or $1.65 \pm 0.9 \%$ per year $(5,26)$. These results are in contrast to our present results showing that 77.36 and $80.49 \%$ of the patient's white and gray matter had become atrophic within 1 year. This discrepancy is probably because of the influence of hypoxia synergizing with neural cell death mechanisms in MSA.

The brain region susceptible to hypoxia is supposed to be the gray matter (12). Some studies have detected white matter damage in the early stage of hypoxic encephalopathy (13-15). In our resuscitated MSA patient, the white matter was damaged almost as severely as the gray matter.

We propose a hypothesis as to why the extensive brain atrophy progressed so rapidly within 10 months, whereas we observed only a slight atrophy 1 month after cardiac arrest and resuscitation. Hypoxic insult triggers alpha-synuclein oligomerization (27). Once the aggregation of alpha-synuclein oligomers begins, the aggregation accelerates and proceeds very rapidly (28). Alphasynuclein is a cytotoxic (29), and expanded alpha-synuclein oligomers might induce neural cell death, manifesting through MRI or CT as brain atrophy. Hypotoxic-ischemic insult might be in itself harmful to neural cells. Alpha-synuclein oligomers might aggravate brain atrophy by their cytotoxicity.

In MSA, glial cytoplasmic inclusion (GCI) shows up mainly in the white matter; however, neuronal cytoplasmic inclusion (NCI) can also be seen in the gray matter (30). Hypoxia-induced misfolded alpha-synucleins accumulate to form GCI and NCI in the white and gray matter, respectively, and might induce neurodegeneration in each region $(31,32)$.

An alternative hypothesis on the rapid and extensive brain atrophy of the MSA patient comes from the fact that atrophic brain images at the end stages of MSA patients are reminiscent of the brain images of patients with prion diseases such as CJD. MSA is a synucleinopathy, and alpha-synuclein is regarded as a prion $(33,34)$. In MSA patients, aggregation of misfolded alpha-synuclein might cause endoplasmic reticulum (ER) stress, which results in nerve cell apoptosis $(31,35)$. Hypoxia, another ER stress inducer $(31,35)$, enhances ER stress and nerve cell apoptosis triggered by toxic alpha-synuclein. Misfolded alphasynuclein spreads through cell-to-cell transmission to cause wide pathological changes $(36,37)$. Extensive brain atrophy might be a manifestation of such pathological changes. Thus, the brain of an MSA patient might develop rapid and severe atrophy under hypoxia in the way that brains with prion diseases do, possibly by common mechanisms.

\section{ETHICS STATEMENT}

Approved by the Hospital Ethics Committee. Written permission was obtained from the patient's next of kin. 


\section{AUTHOR CONTRIBUTIONS}

$\mathrm{SN}, \mathrm{HM}$, and YK planned and designed the study; SN, HM, and YK acquired and analyzed the data; and SN wrote the manuscript. All authors approved submission of the manuscript.

\section{REFERENCES}

1. Low PA, Reich SG, Jankovic J, Shults CW, Stern MB, Novak P, et al. Natural history of multiple system atrophy in the USA: a prospective cohort study. Lancet Neurol (2015) 14:710-9. doi:10.1016/S1474-4422(15)00058-7

2. Gilman S, Low P, Quinn N, Albanese A, Ben-Shlomo Y, Fowler C, et al. Consensus statement on the diagnosis of multiple system atrophy. American Autonomic Society and American Academy of Neurology. Clin Auton Res (1998) 8:359-62. doi:10.1007/BF02309628

3. Petrovic IN, Ling H, Asi Y, Ahmed Z, Kukkle PL, Hazrati LN, et al. Multiple system atrophy-parkinsonism with slow progression and prolonged survival: a diagnostic catch. Mov Disord (2012) 27:1186-90. doi:10.1002/mds.25115

4. Gilman S, Wenning GK, Low PA, Brooks DJ, Mathias CJ, Trojanowski JQ, et al. Second consensus statement on the diagnosis of multiple system atrophy. Neurology (2008) 71:670-6. doi:10.1212/01.wnl.0000324625.00404.15

5. Guevara C, Bulatova K, Barker GJ, Gonzalez G, Crossley N, Kempton MJ. Whole-brain atrophy rate in idiopathic Parkinson's disease, multiple system atrophy, and progressive supranuclear palsy. Parkinsons Dis (2016) 2016:9631041. doi:10.1155/2016/9631041

6. Bhattacharya K, Saadia D, Eisenkraft B, Yahr M, Olanow W, Drayer B, et al. Brain magnetic resonance imaging in multiple-system atrophy and Parkinson disease: a diagnostic algorithm. Arch Neurol (2002) 59:835-42. doi:10.1001/ archneur.59.5.835

7. Saeed U, Compagnone J, Aviv RI, Strafella AP, Black SE, Lang AE, et al. Imaging biomarkers in Parkinson's disease and parkinsonian syndromes: current and emerging concepts. Transl Neurodegener (2017) 6:8. doi:10.1186/ s40035-017-0076-6

8. Gama RL, Távora DF, Bomfim RC, Silva CE, Bruin VM, Bruin PF. Morphometry in the differential diagnosis of parkinsonian syndromes. Arq Neuropsiquiatr (2010) 68:333-8. doi:10.1590/S0004-282X2010000300001

9. Wüllner U, Weller M, Kornhuber J, Bornemann A, Schulz JB, Riederer P, et al. Altered expression of calcium- and apoptosis-regulating proteins in multiple system atrophy Purkinje cells. Mov Disord (2000) 15:269-75. doi:10.1002/1531-8257(200003)15:2<269::AID-MDS1009>3.0.CO;2-0

10. Stefanova N, Wenning GK. Review: Multiple system atrophy: emerging targets for interventional therapies. Neuropathol Appl Neurobiol (2016) 42:20-32. doi:10.1111/nan.12304

11. HayashiM, ArakiS, Kumada S, Itoh M, Satoh J, Morimatsu Y.Neurodegenerative features in developmental brain disorders. Neuropathology (2001) 21:32-9. doi:10.1046/j.1440-1789.2001.00366.x

12. Weiss N, Galanaud D, Carpentier A, Naccache L, Puybasset L. Clinical review: Prognostic value of magnetic resonance imaging in acute brain injury and coma. Crit Care (2007) 11:230. doi:10.1186/cc6107

13. Gerdes JS, Walther EU, Jaganjac S, Makrigeorgi-Butera M, Meuth SG, Deppe M. Early detection of widespread progressive brain injury after cardiac arrest: a single case DTI and post-mortem histology study. PLoS One (2014) 9:e92103. doi:10.1371/journal.pone.0092103

14. Chalela JA, Wolf RL, Maldjian JA, Kasner SE. MRI identification of early white matter injury in anoxic-ischemic encephalopathy. Neurology (2001) 56:481-5. doi:10.1212/WNL.56.4.481

15. Arbelaez A, Castillo M, Mukherji SK. Diffusion-weighted MR imaging of global cerebral anoxia. AJNR Am J Neuroradiol (1999) 20:999-1007.

16. Horstmann A, Frisch S, Jentzsch RT, Müller K, Villringer A, Schroeter ML. Resuscitating the heart but losing the brain: brain atrophy in the aftermath of cardiac arrest. Neurology (2010) 74:306-12. doi:10.1212/ WNL.0b013e3181cbcd6f

17. Hirata Y, Matsuda H, Nemoto K, Ohnishi T, Hirao K, Yamashita F, et al. Voxelbased morphometry to discriminate early Alzheimer's disease from controls. Neurosci Lett (2005) 382:269-74. doi:10.1016/j.neulet.2005.03.038

\section{ACKNOWLEDGMENTS}

We thank Dr. Jun Ogura for information on the patient; Drs. Shizuo Oi, Kumiko Ando, and Satoshi Mori for pertinent comments, and Enago for the English-language review.

18. Sakurai K, Imabayashi E, Tokumaru AM, Hasebe S, Murayama S, Morimoto S, et al. The feasibility of white matter volume reduction analysis using SPM8 plus DARTEL for the diagnosis of patients with clinically diagnosed corticobasal syndrome and Richardson's syndrome. Neuroimage Clin (2014) 7:605-10. doi:10.1016/j.nicl.2014.02.009

19. Shimoda K, Kimura M, Yokota M, Okubo Y. Comparison of regional gray matter volume abnormalities in Alzheimer's disease and late life depression with hippocampal atrophy using VSRAD analysis: a voxel-based morphometry study. Psychiatry Res (2015) 232:71-5. doi:10.1016/j.pscychresns.2015.01.018

20. Nagayama H, Ueda M, Yamazaki M, Nishiyama Y, Hamamoto M, Katayama Y. Abnormal cardiac [(123)I]-meta-iodobenzylguanidine uptake in multiple system atrophy. Mov Disord (2010) 25:1744-7. doi:10.1002/mds.23338

21. Druschky A, Hilz MJ, Platsch G, Radespiel-Tröger M, Druschky K, Kuwert T, et al. Differentiation of Parkinson's disease and multiple system atrophy in early disease stages by means of I-123-MIBG-SPECT. J Neurol Sci (2000) 175:3-12. doi:10.1016/S0022-510X(00)00279-3

22. Köllensperger M, Seppi K, Liener C, Boesch S, Heute D, Mair KJ, et al. Diffusion weighted imaging best discriminates PD from MSA-P: a comparison with tilt table testing and heart MIBG scintigraphy. Mov Disord (2007) 22:1771-6. doi:10.1002/mds.21614

23. Chung EJ, Kim SJ. (123)I-Metaiodobenzylguanidine myocardial scintigraphy in Lewy body-related disorders: a literature review. J Mov Disord (2015) 8:55-66. doi:10.14802/jmd.15015

24. Armstrong MJ, Litvan I, Lang AE, Bak TH, Bhatia KP, Borroni B, et al. Criteria for the diagnosis of corticobasal degeneration. Neurology (2013) 80:496-503. doi:10.1212/WNL.0b013e31827fofd1

25. Litvan I, Agid Y, Calne D, Campbell G, Dubois B, Duvoisin RC, et al. Clinical research criteria for the diagnosis of progressive supranuclear palsy (SteeleRichardson-Olszewski syndrome): report of the NINDS-SPSP international workshop. Neurology (1996) 47:1-9. doi:10.1212/WNL.47.1.1

26. Guevara C, Bulatova K, Soruco W, Gonzalez G, Farías GA. Retrospective diagnosis of parkinsonian syndromes using whole-brain atrophy rates. Front Aging Neurosci (2017) 9:99. doi:10.3389/fnagi.2017.00099

27. Chen T, Li J, Chao D, Sandhu HK, Liao X, Zhao J, et al. $\delta$-Opioid receptor activation reduces $\alpha$-synuclein overexpression and oligomer formation induced by MPP(+) and/or hypoxia. Exp Neurol (2014) 255:127-36. doi:10.1016/j. expneurol.2014.02.022

28. Luk KC, Kehm VM, Zhang B, O’Brien P, Trojanowski JQ, Lee VM. Intracerebral inoculation of pathological $\alpha$-synuclein initiates a rapidly progressive neurodegenerative $\alpha$-synucleinopathy in mice. J Exp Med (2012) 209:975-86. doi:10.1084/jem.20112457

29. Bendor JT, Logan TP, Edwards RH. The function of $\alpha$-synuclein. Neuron (2013) 79:1044-66. doi:10.1016/j.neuron.2013.09.004

30. Cykowski MD, Coon EA, Powell SZ, Jenkins SM, Benarroch EE, Low PA, et al. Expanding the spectrum of neuronal pathology in multiple system atrophy. Brain (2015) 138:2293-309. doi:10.1093/brain/awv114

31. Xu C, Bailly-Maitre B, Reed JC. Endoplasmic reticulum stress: cell life and death decisions. J Clin Invest (2005) 115:2656-64. doi:10.1172/JCI26373

32. Unal-Cevik I, Gursoy-Ozdemir Y, Yemisci M, Lule S, Gurer G, Can A, et al. Alpha-synuclein aggregation induced by brief ischemia negatively impacts neuronal survival in vivo: a study in [A30P] alpha-synuclein transgenic mouse. J Cereb Blood Flow Metab (2011) 31:913-23. doi:10.1038/jcbfm.2010.170

33. Luna E, Luk KC. Bent out of shape: $\alpha$-synuclein misfolding and the convergence of pathogenic pathways in Parkinson's disease. FEBS Lett (2015) 589:3749-59. doi:10.1016/j.febslet.2015.10.023

34. Prusiner SB, Woerman AL, Mordes DA, Watts JC, Rampersaud R, Berry DB, et al. Evidence for $\alpha$-synuclein prions causing multiple system atrophy in humans with parkinsonism. Proc Natl Acad Sci U S A (2015) 112:E5308-17. doi:10.1073/pnas.1514475112 
35. Szabo A, Kovacs A, Riba J, Djurovic S, Rajnavolgyi E, Frecska E. The endogenous hallucinogen and trace amine N,N-dimethyltryptamine (DMT) displays potent protective effects against hypoxia via sigma-1 receptor activation in human primary iPSC-derived cortical neurons and microglia-like immune cells. Front Neurosci (2016) 10:423. doi:10.3389/fnins.2016. 00423

36. Polymenidou M, Cleveland DW. Prion-like spread of protein aggregates in neurodegeneration. J Exp Med (2012) 209:889-93. doi:10.1084/jem.20120741

37. Recasens A, Dehay B. Alpha-synuclein spreading in Parkinson's disease. Front Neuroanat (2014) 8:159. doi:10.3389/fnana.2014.00159
Conflict of Interest Statement: The authors declare that the research was conducted in the absence of any commercial or financial relationships that could be construed as a potential conflict of interest.

Copyright (c) 2018 Nisitani, Miyoshi and Katsuoka. This is an open-access article distributed under the terms of the Creative Commons Attribution License (CC BY).

The use, distribution or reproduction in other forums is permitted, provided the original author(s) or licensor are credited and that the original publication in this journal is cited, in accordance with accepted academic practice. No use, distribution or reproduction is permitted which does not comply with these terms. 